\title{
Spatial and Temporal Drought Analysis in the North Central Region of Nigeria
}

\author{
*1OKEKE, TC; ${ }^{2}$ OKEOLA, OG \\ *I Civil Engineering Department, Federal University Oye-Ekiti, Ekiti State, Nigeria \\ ${ }^{2}$ Water Resources \& Environmental Engineering Dept, University of Ilorin, Kwara State, Nigeria \\ *Corresponding Author Email: tochukwu.okeke@fuoye.edu.ng
}

\begin{abstract}
This study examined the occurrence of drought in north central Nigeria. Problems related to drought includes: unpredictable commencement and end time of rainfall season, seasonal rainfall fluctuations, long period of no rainfall. Monthly rainfall data was obtained from the Nigeria Metrological Agency (NIMET) Lagos. This covers up to 51 years for seven different metrological stations namely: Lafia, Ilorin, Markurdi, Jos, Lokoja, and Minna and Abuja. Standardized Precipitation Index (SPI) was adopted for this study. SPI approach requires a transformation to the initial distribution of rainfall to achieve a normalized distribution. Drought analysis indicates 1980s as the decade with worst drought effect as drought incidences were observed in Jos, Minna, Ilorin and Markurdi stations and 1983 as the only year in which drought occurred simultaneously across four different stations.
\end{abstract}

DOI: https://dx.doi.org/10.4314/jasem.v23i4.30

Copyright: Copyright (O) 2019 Okeke and Okeola. This is an open access article distributed under the Creative Commons Attribution License (CCL), which permits unrestricted use, distribution, and reproduction in any medium, provided the original work is properly cited.

Dates: Received: 23 February 2019; Revised: 29 March 2019; Accepted 15 April 2019

Keywords: Drought Risk, Standardized Precipitation Index (SPI), Metrological Drought, Time Scale.

Drought can also be defined as a negative imbalance between precipitation and evapotranspiration in a particular area (Bordi et al., 2001), and is classified into three parts namely: metrological, agricultural and hydrological with precipitation as the primary variable (Dai, 2011). Secondary variable include surface air temperature which accounts for the effect of evaporation in meteorological drought. Meteorological drought generally triggers agricultural and hydrological droughts since its measure relates to below-normal precipitation (Wang et al., 2016). Prolonged absence of rainfall results in below-normal precipitation, and Standardized Precipitation Index (SPI) provides a good measure of this.

SPI is a tool for the analysis of the possibility of drought in any given station. SPI can be estimated for different time scales. These time scales are: weekly, monthly, quarterly, and yearly (Nashrrullah, 2004). Mckee et al., (1993) recommends a period of at least 30 years. A drought event is likely any time the SPI is continuously negative and reaches intensity of -1.0 or less (Mahajan \& Dodamani, 2016). A functional definition of drought can be established for each time scale. Several authors have used SPI as a tool for drought monitoring since it indicates both wet and dry condition. NIMET (2013) used SPI for the prediction of seasonal rainfall in Nigeria. The SPI values were mapped with different colors indicating varying wet and dry condition all over the country. The months of
July, August and September were identified as the peak of raining season for the year. Bordi et al., (2001) examined drought conditions in Italy using standardized precipitation index on different time scales for August 2000. Gamma distribution function was fitted into precipitation data. Efforts at combining SPI with other drought indices is exemplified in work of Murad and Islam (2011) where SPI and Normalized Difference Vegetation Index (NDVI) agricultural drought in the north-west region which is the most drought prone area of Bangladesh. A resultant risk map was obtained by integrating agriculture and meteorological drought risk maps which indicate the areas facing a combined drought. Rainfall effect on agro-business is in form of agricultural drought. Agricultural drought as a period with dry soils that results from below-average precipitation (Dai, 2011). Below-average precipitation results in insufficient rainfall for growing crops which affects plant growth and good yield. Standardized Precipitation Index (SPI) presents a useful formulation for the definition of drought based on rainfall average value. Also, abovenormal evaporation can leads to the wilting and drying up of crop leaves. Dai (2011) also observed that a lack of precipitation often triggers agricultural droughts, but other factors, including more intense but less frequent precipitation, poor water management, and erosion, can cause or enhance this drought. Agricultural drought is pronounced in areas with 
limited access to advanced irrigation facility where manual cultivation is the order.

The objectives of this study is to standardized the procedure for the determination of SPI and assess the metrological drought of the states within the north central region.

\section{MATERIALS AND METHODOLOGY}

Study Area: North central Nigeria (Figure 1) lies approximately between longitudes $3^{\circ}$ and $14^{\circ} \mathrm{E}$ and latitudes $7^{0}$ and $10^{\circ} \mathrm{N}$ and is part of middle belt region. This region is made up of 6 states namely Benue, Kwara, Niger, Plateau, Nassarawa, Kogiand Abuja (the Federal Capital Territory). The tropical savannah climate of north central Nigeria is characterized by a long dry season. The vegetation of the region is characterized by scattered tall trees and shrubs typical of southern guinea savannah vegetation. Different crop types such as tuber crops, cash crops, rice survive well in the region.

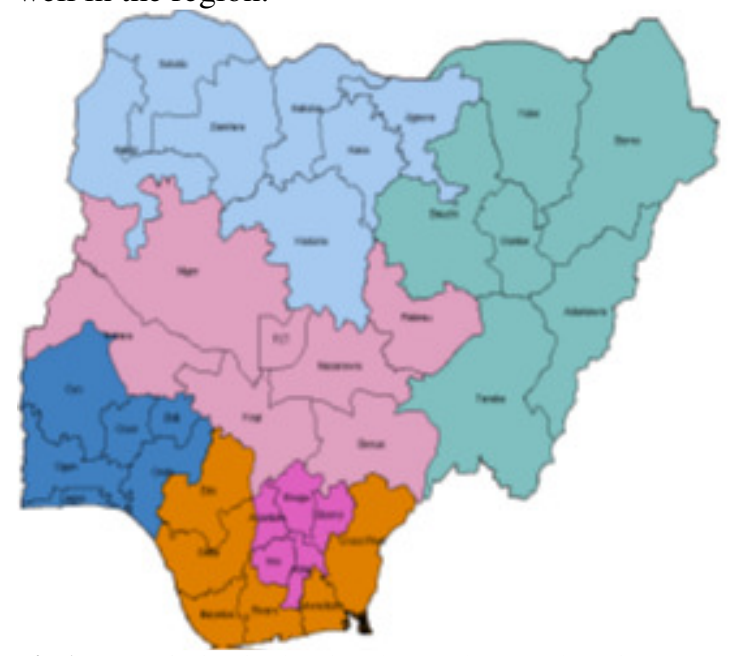

Fig 1: Map of Nigeria showing the North Central Region

Data Collection and Reduction: The location and durations of rainfall data used for this study are given in Table 1.

Table 1: States and Rainfall Data Period

\begin{tabular}{llll}
\hline S/n & Met Station & State & Period \\
\hline 1 & Ilorin & Kwara & $1960-2010$ \\
2 & Markurdi & Benue & $1960-2010$ \\
3 & Minna & Niger & $1960-2010$ \\
4 & Jos & Plateau & $1960-2010$ \\
5 & Lokoja & Kogi & $1960-2010$ \\
6 & Abuja & F.C.T & $1982-2010$ \\
7 & Lafia & Nassarrawa & $2000-2010$ \\
\hline
\end{tabular}

Standardized Precipitation Index: Standardized Precipitation Index (SPI), a tool derived by McKee, et al., (1993) used for measuring the risk effect of metrological drought. Dai (2010) identified Palmer
Drought Severity Index (PDSI), Standardized Precipitation Index (SPI) and Rainfall Deciles (RD) as suitable for the analysis of metrological drought. The advantage of SPI is that only rainfall data is required. Rainfall data ranging from 10 to 50 years obtained from Nigeria metrological agency was used for the computation of SPI. Precipitation is typically not normally distributed for accumulation periods of 12 months or less, therefore applying a transformation to the distribution will help overcome this challenge. The transformation of original precipitation values into the SPI intends to (Mckee, et al., (1993): (a) shifting the mean of the data to have a transformed mean of zero. (b) Shifting the standard deviation of the data to have a transformed value of 1.0 , and (c) Reducing the skew existing in the data towards zero.

Karavitis, (2011) stated that a continuous random variable $X$ follows a gamma distribution if the probability distribution function of $\mathrm{X}$ is:

$C G T=G(x, \alpha, \beta)=\frac{1}{\beta^{\alpha} \Gamma(\alpha)} \int_{0}^{x} x^{\alpha-1} e^{\frac{-x}{\beta}} d x$

Where CGT $=$ cumulative gamma transform; $\alpha=$ ShapeParameter $; \quad \beta=$ ScaleParameter $; \quad x=$ AnnualPrecipitationAmount

$\Gamma \sigma=$ GammaFunction $=\int_{0}^{x} x^{\sigma-1} e^{-x} d x$

The maximum likelihood is used to estimate $\sigma$ and $\beta$ thus:

$\alpha=$ ShapeParameter $=\frac{1}{4 U}\left[1+\sqrt{1+\left(\frac{4 U}{3}\right)}\right]$

$\beta=$ ScaleParameter $=\frac{\bar{X}}{\beta}$

Where

$U=\ln (X)-\bar{X}_{l n}$

$\bar{X}_{l n}=\frac{\sum \ln (X)}{N}$

$\bar{X}=\frac{\sum X}{N}$

$\mathrm{N}=$ no of precipitation observations; $x=$ AnnualPrecipitationAmount

The obtained parameters $\alpha, \beta$ and $U$ are then used to find the cumulative probability of an observed precipitation event for the given year in the series by applying these parameters into the gamma probability density function. 
$G(x)=\int_{0}^{x} g(x) d x=\frac{1}{\beta^{\alpha} \Gamma(\alpha)} \int_{0}^{x} x^{\alpha-1} e^{\frac{-x}{\beta}} d x$

And as an excel function, Gammatransform = $\operatorname{GAMMADIST}(x, \alpha, \beta, T R U E)$.

The cumulative probability distribution function is converged into the standard normal cumulative distribution function so that both of them have the same probability To avoid graph solution, the SPI is applied using the following equations (Chortaria, et al., (2010):

$t=\sqrt{\ln \left[\frac{1}{\left(G_{x}\right)^{2}}\right]} \quad$ For $0<G_{X} \leq 0.5$

$t=\sqrt{\ln \left[\frac{1}{\left(1-X_{g}\right)^{2}}\right]} \quad$ For $0.5<G_{X} \leq 1$

The Gamma transformed values are are again transformed, with different formulae as shown below,
$S P I=-\left[t-\frac{c_{0}+c_{1} t+c_{2} t^{2}}{1+d_{1} t+d_{2} t^{2}+d_{3} t^{3}}\right] \quad$ For $\quad 0<G_{X} \leq 0.5$

$S P I=+\left[t-\frac{c_{0}+c_{1} t+c_{2} t^{2}}{1+d_{1} t+d_{2} t^{2}+d_{3} t^{3}}\right] \quad$ For $0.5<G_{X}<1.0$

Where $\mathrm{t}=$ ttransform; $\mathrm{C}_{0}=2.515517, \mathrm{c}_{1}=0.802853, \mathrm{c}_{2}$ $=0.010328, \mathrm{~d}_{1}=1.432788, \mathrm{~d}_{2}=0.189269, \mathrm{~d}_{3}=$ 0.001308

\section{RESULT AND DISCUSSION}

Standardized Precipitation Index (SPI): Standardised precipitation index (SPI) was used for the analysis of the drought effect of annual rainfall in the various stations. The negative values indicates negative values indicates years with rainfall distribution ranging from near normal to extremely dry condition. The Figures 2 to 8 show the SPI values for the different stations.

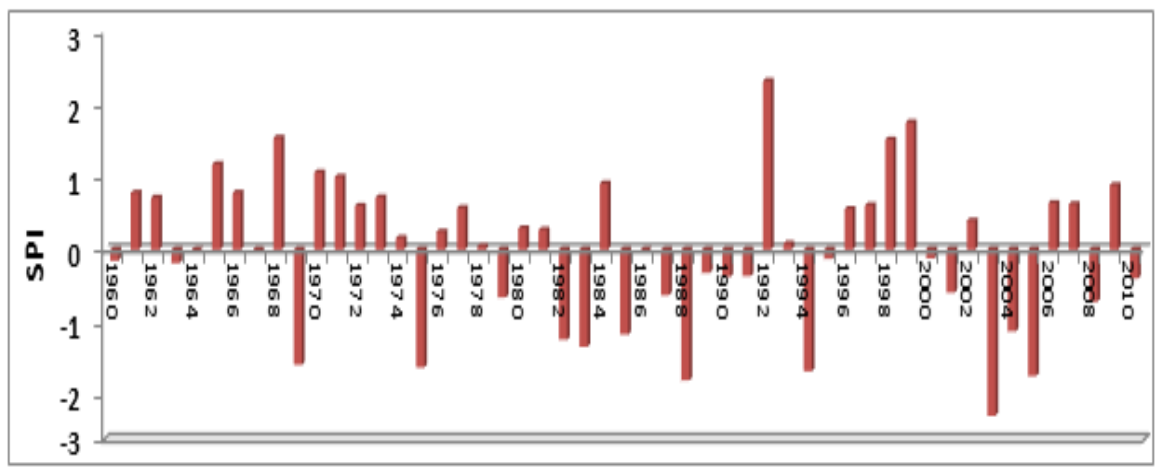

Fig 2: SPI Chart for Markurdi Metrological Station

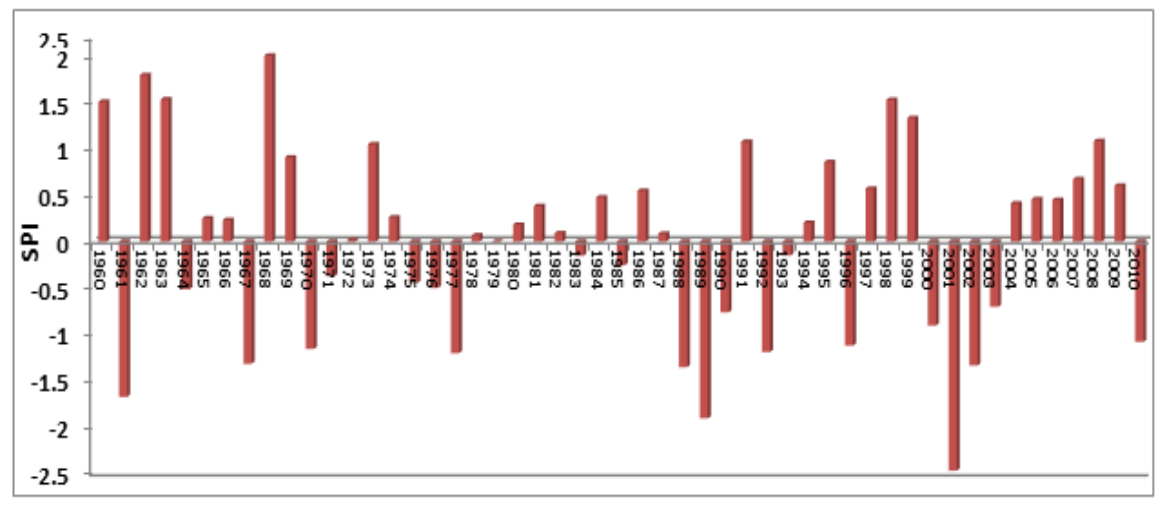

Fig 3: SPI Chart for Ilorin Metrological Station 


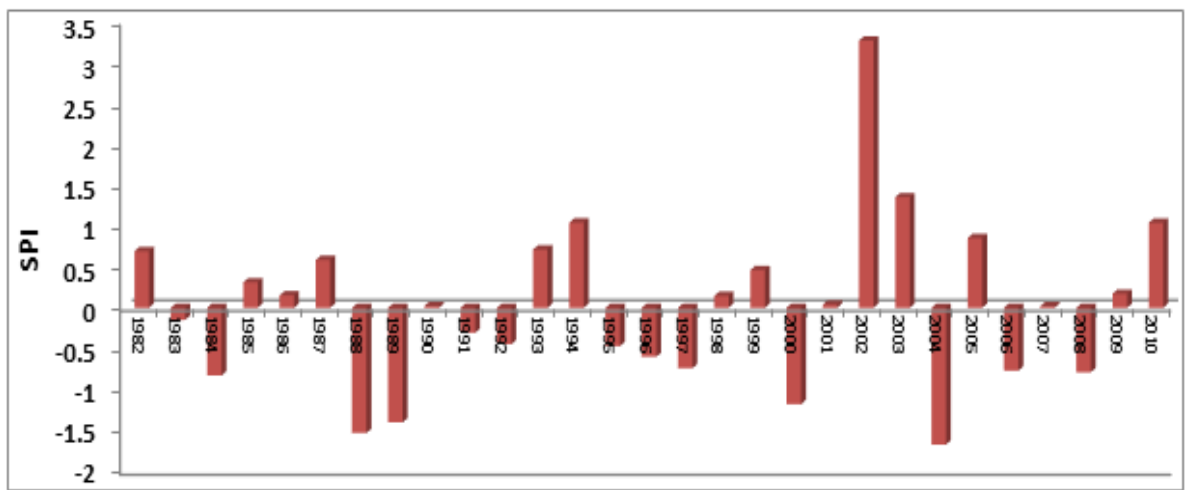

Fig 4: SPI Chart for Abuja Metrological Station

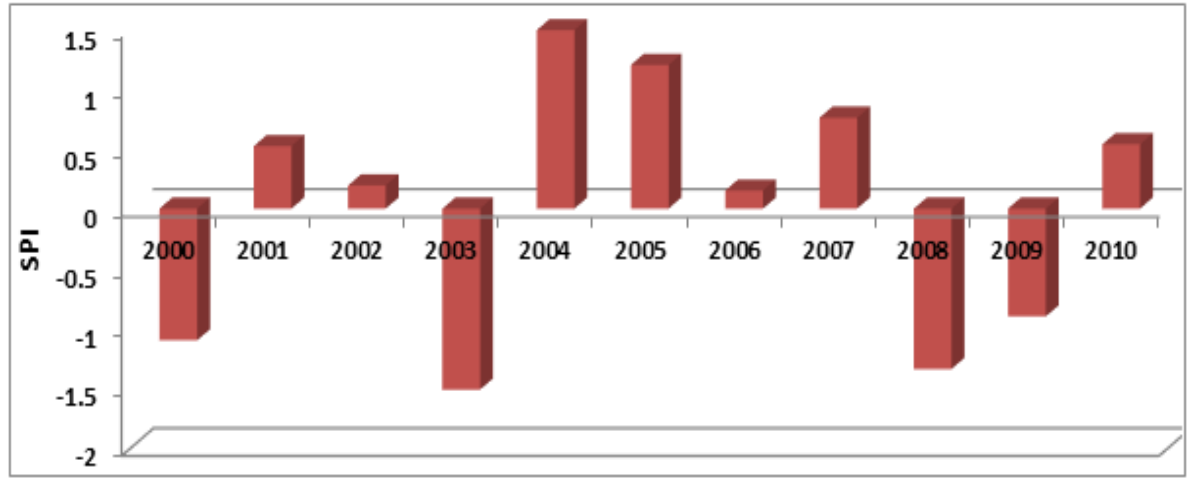

Fig 5: SPI Chart for Lafia Metrological Station

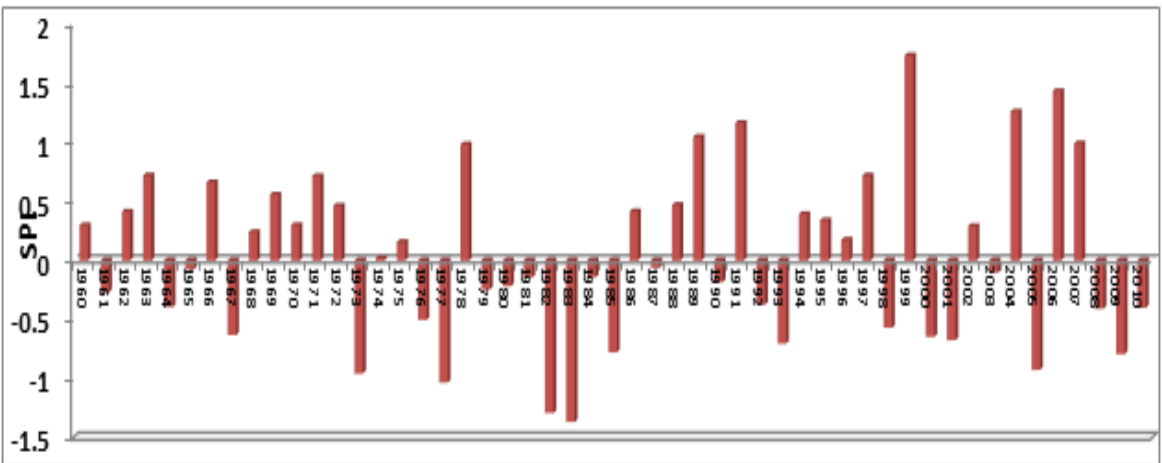

Fig 6: SPI Chart for Lokoja Metrological Station

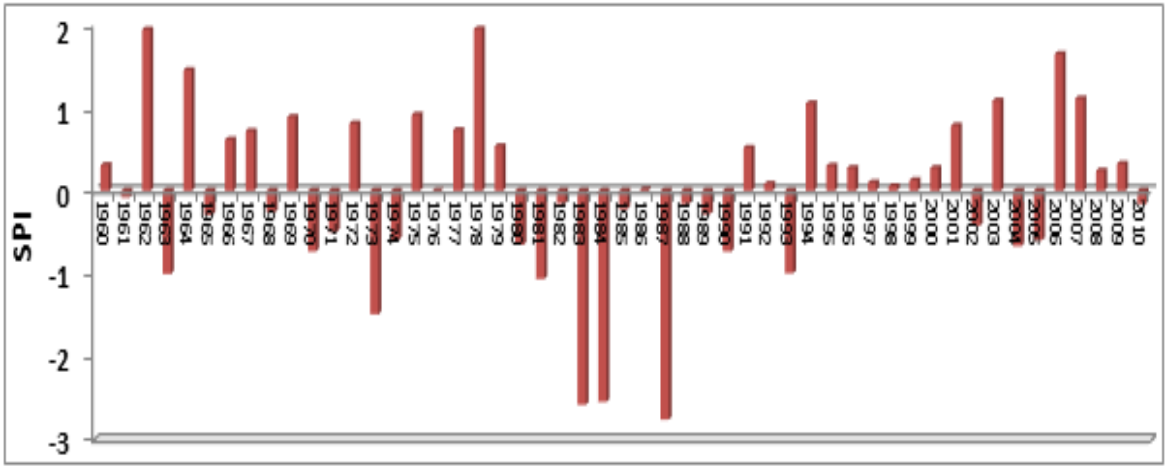

Fig 7: SPI Chart for Minna Metrological Station

OKEKE, TC; OKEOLA, OG 


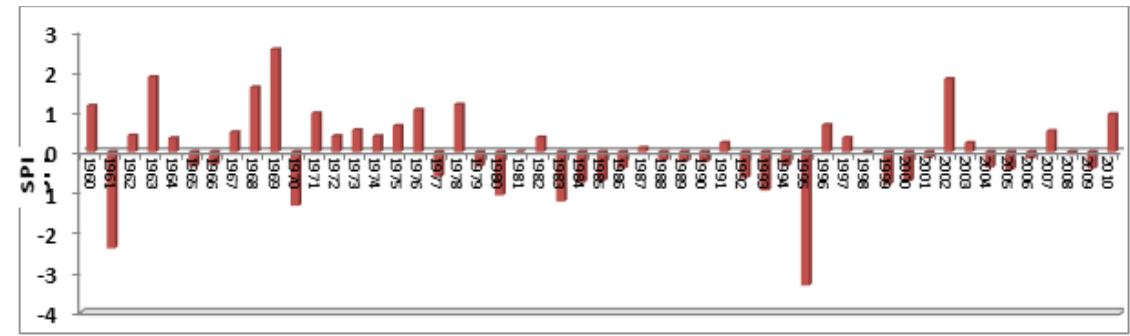

Fig 8: SPI chart for Jos Metrological Station

Table 2: SPI Metrological Drought Risk Assessment for the Stations

\begin{tabular}{lllll}
\hline S/n & Station & Moderately Dry & Severely Dry & Extremely Dry \\
\cline { 3 - 4 } 1 & Jos & $1970,1980,1983$ & None & 1961,1995 \\
2 & Markurdi & $1982,1983,1985$ & $1969,1975,1988$ & $20032004,1994,2005$ \\
3 & Ilorin & $1967,1970,1972$ & 1961,19892001 & $1977,1988,19921996,2002,2010$ \\
4 & Abuja & 1989,2000 & 1998,2004 & None \\
5 & Lafia & 2000,2008 & 2003 & None \\
6 & Lokoja & $1977,1982,1983$ & None & None \\
7 & Minna & $1963,1973,1981$ & None & $1983,1984,1987$ \\
\hline
\end{tabular}

The following are observations on Table 2: (i) Stations that experineced moderately to extremely dry condition simulteously over a two years period includes; Markurdi (moderately dry condition between 1982 and 1983); Lokoja (moderately dry condition between 1982 and 1983); and Minna (extreme dery condition between 1983 to 1984); and (ii) 1983 is the only year in which moderate to extreme drought occurred simulteneously in four different stations. The stations are Jos, Minna, and Lokoja and Markurdi. (iii) Minna and Jos recorded the highest number of extreme and severe drought events in the region. (iv) 1995 is the year in which the worst extreme SPI value of -3.32 which occurred in Jos station.

Conclusion: With the observation of moderate to extreme drought in states within the region an appropriate management strategy must be adopted to mitigate this negative effects, as there is always the possibility of a repeat occurance.

\section{REFERENCES}

Bordi, I; Frigo, S; Parentti, P; Parranza, A; and Sutera, A. (2001). The Analysis of Standardized Precipitation Index in Mediterrean Area: Large Scale Pattern. Annali di geofisca. 14(6): 965-978.

Chortoria, C; Karavitis, C.A; Alexandris, S. (2010). The Development of SPI Drought Index for Greece Using Geo-Statistical Method. A paper presented at BALWOIS 2010 Ohrid, Republic of Mecedonia.

Dai, A. (2011).Drought Under Global Warming: A Review. John Willey and Sons Ltd. 2: 45-65.
Karavitis, A .C; Alexandria, S; Tsesmelis, D.E; Athanasopoulos, G (2011). Water Journal. 3(2): 787- 805 .

Mahajan, D.R; Dodamani, B.M (2016) Spatial and Temporal Drought Analysis in the Krishna River Basin of Maharashtra, India. Cogent Engineering. 3: $1-15$.

McKee, T. B; Doesken, N. J; and Kleist, J (1993).The Relationship of Drought Frequency and Duration to Time Scales. Preprints, 8th Conference on Applied Climatology, January 17-22, Anaheim, California.

Murad, H; Islam, A.K (2011).Drought Assessment Using Remote Sensing and Gis in North-West Region of Bangladesh. 3rd International Conference on Water \& Flood Management.

NIMET (2013). 2013 Seasonal Rainfall Prediction. Nigerian Metrological Agency. 1-43

Nashurrullah, S. (2004). Meteorological Data Indices. Geoinformatic Center, Asian Institute of Technology, Japan.

Wang, W; Ertsen, M.W; Svoboda, M.D; Hafeez, M (2016) Propagation of Drought: From Meteorological Drought to Agricultural and Hydrological Drought. Advances in Meteorology: $1-5$. 